\title{
Video Article \\ Manufacturing Simple and Inexpensive Soil Surface Temperature and Gravimetric Water Content Sensors
}

\author{
Armin Howell ${ }^{1}$, Colin Tucker ${ }^{1}$, Edmund E. Grote ${ }^{1}$, Maik Veste ${ }^{2,3}$, Jayne Belnap ${ }^{1}$, Gerhard Kast ${ }^{4}$, Bettina Weber ${ }^{5,6}$, Sasha C. Reed ${ }^{1}$ \\ ${ }^{1}$ Southwest Biological Science Center, U.S. Geological Survey \\ ${ }^{2}$ Centre for Energy Technology Brandenburg \\ ${ }^{3}$ Institute of Environmental Sciences, Brandenburg University of Technology Cottbus-Senftenberg \\ ${ }^{4}$ Umweltanalytische Produkte $\mathrm{GmbH}$ \\ ${ }^{5}$ Institute of Plant Sciences, University of Graz \\ ${ }^{6}$ Multiphase Chemistry Department, Max Planck Institute for Chemistry
}

Correspondence to: Armin Howell at ahowell@usgs.gov

URL: https://www.jove.com/video/60308

DOI: doi:10.3791/60308

Keywords: Environmental Sciences, Issue 154, biocrust, microclimate, moisture, resistance, resistivity, soil surface, thermocouple

Date Published: 12/21/2019

Citation: Howell, A., Tucker, C., Grote, E.E., Veste, M., Belnap, J., Kast, G., Weber, B., Reed, S.C. Manufacturing Simple and Inexpensive Soil Surface Temperature and Gravimetric Water Content Sensors. J. Vis. Exp. (154), e60308, doi:10.3791/60308 (2019).

\section{Abstract}

Quantifying temperature and moisture at the soil surface is essential for understanding how soil surface biota respond to changes in the environment. However, at the soil surface these variables are highly dynamic and standard sensors do not explicitly measure temperature or moisture in the upper few millimeters of the soil profile. This paper describes methods for manufacturing simple, inexpensive sensors that simultaneously measure the temperature and moisture of the upper $5 \mathrm{~mm}$ of the soil surface. In addition to sensor construction, steps for quality control, as well as for calibration for various substrates, are explained. The sensors incorporate a Type $\mathrm{E}$ thermocouple to measure temperature and assess soil moisture by measuring the resistance between two gold-plated metal probes at the end of the sensor at a depth of $5 \mathrm{~mm}$. The methods presented here can be altered to customize probes for different depths or substrates. These sensors have been effective in a variety of environments and have endured months of heavy rains in tropical forests as well as intense solar radiation in deserts of the southwestern U.S. Results demonstrate the effectiveness of these sensors for evaluating warming, drying, and freezing of the soil surface in a global change experiment.

\section{Video Link}

The video component of this article can be found at https://www.jove.com/video/60308/

\section{Introduction}

Environmental sensors are critical tools for assessing, monitoring, and understanding ecosystem dynamics. Temperature and moisture are fundamental drivers of biological processes in soils and influence the activity and community composition of soil organisms ${ }^{1,2}$. Additionally, temperature and moisture have been shown to affect the timing of seedling emergence and litter decomposition rates $3,4,5$. In dryland ecosystems, soil surfaces not covered by vascular plants are often topped with communities of mosses, lichens, and cyanobacteria, known as a biological soil crust (biocrust) (Figure 1). These communities exist at the soil surface and rarely penetrate deeper than a few millimeters into the soil ${ }^{6}$. Biological soil crusts can strongly influence soil stabilization, water infiltration and evaporation rates, albedo, temperature, nutrient cycling, and soil-atmosphere $\mathrm{CO}_{2}$ exchange $e^{7,8,9}$. In turn, for some systems the activity of these surface communities can dominate overall soil attributes and the rates of various processes ${ }^{10}$. Sensors that explicitly focus measurements on shallow depths can help us further understand how surficial temperature and moisture affect seed germination, decomposition rates, and responses of soil surface biota, as well as many other ecosystem functions.

Recent developments in soil sensor technology have shown the importance of spatially explicit measurements for understanding biological processes at the soil surface ${ }^{11,12}$. Conventional methods for analyzing soil moisture incorporate sensors placed below the soil surface and often integrate measurements across depths. The soil moisture recorded by these probes can help inform our understanding of environmental controls on soil organisms, but likely miss many of the nuances occurring at the soil surface. To explicitly measure water content of the top few millimeters of soil, Weber et al. recently developed biocrust wetness probes (BWP) that determine soil moisture via electrical conductivity of the soil surface to a depth of $3 \mathrm{~mm}^{11}$. Using Weber's sensors in conjunction with 0 to $5 \mathrm{~cm}$ integrated moisture probes, Tucker et al. demonstrated the importance of moisture sensors that focus on the top few millimeters of the soil surface. In particular, small precipitation events, which were highly relevant to the activity of biocrust communities, did not register for the $0-50 \mathrm{~mm}$ (i.e., $5 \mathrm{~cm}$ ) integrated probes and were only detected by the BWPs ${ }^{12}$. Sensors focused on the top few millimeters of soils are essential to measure moisture events that are not large enough to infiltrate past the surface but are sufficient to induce responses from the biota at the surface. 
Soil surface temperature is another important environmental factor driving physiological processes. Diurnal soil surface temperatures can be highly variable, especially in plant interspaces where the unshaded soil surface is exposed to large quantities of solar radiation. Also, temperature is more variable at the soil surface than deeper in the soil profile ${ }^{13}$ or the air ${ }^{14}$. For example, Tucker et al. showed a maximum diurnal soil surface temperature range of nearly $60^{\circ} \mathrm{C}\left(13-72^{\circ} \mathrm{C}\right)$ occurring over only $24 \mathrm{~h}$. These temperatures were measured using thermocouples inserted $3 \mathrm{~mm}$ into the soil surface. Meanwhile, nearby temperature probes $50 \mathrm{~mm}$ deep measured a range of only $30{ }^{\circ} \mathrm{C}(22-52$ ${ }^{\circ} \mathrm{C}$ ) during the same day ${ }^{12}$. The thermocouples explicitly measuring temperature at the soil surface showed much higher variation than sensors at $50 \mathrm{~mm}$ depths, as the surface soils were $10{ }^{\circ} \mathrm{C}$ colder at night and $20^{\circ} \mathrm{C}$ warmer during the heat of the day relative to the $50 \mathrm{~mm}$ deep values.

Temperature represents a critical control over physiological processes. For example, at constant soil moistures in laboratory conditions, $\mathrm{CO}_{2}$ losses from soil increase dramatically with increasing temperatures in most ecosystems ${ }^{2,15,16}$. Similarly, data from field climate manipulation studies that aim to increase plot temperatures relative to controls have shown that warmed soils release more $\mathrm{CO}_{2}$ than nearby unheated soils (at least in the first years of treatments ${ }^{17,18}$ ) and that biocrusted soils show a similar response to warming ${ }^{7,9}$. Both temperature and moisture have been demonstrated to be important environmental variables and sensors that can accurately capture soil surface climatic conditions can elucidate how they influence the physiological processes of organisms at the soil surface ${ }^{11,12}$.

This paper presents sensors designed to measure both temperature and moisture to a $5 \mathrm{~mm}$ depth below the soil surface, offering significant power in assessing how these variables interact with and drive biological responses from surficial biota. The Type $E$ thermocouple is made of two metals (chromel and constantan), and temperature changes in the metals create different voltages that are recorded by a data logger. The soil moisture sensor measures resistance between two gold-plated metal prongs. Resistance is affected by soil water content, because more water increases conductance and thus decreases resistance between the prongs. Following the design of Weber et al. ${ }^{11}$, these sensors measure soil moisture to a depth of $5 \mathrm{~mm}$ and additionally include a thermocouple to measure temperature on the same probe. These sensors allow a refined view of how temperature and moisture dynamics vary in concert at the soil surface using a single probe. These probes provide myriad opportunities to explore how organisms living at the surface respond to changes in their environment. An additional benefit of these sensors is that they are relatively simple and inexpensive to build and calibrate, and researchers will be readily able to adopt their use.

The following protocol describes in detail the materials and methods for constructing the sensors, including an outline for connecting the sensors to data loggers. These sensors used commercially available loggers, but any data logger that can be attached to a multiplexer could be used. Methods for calibrating the sensors to the substrates of interest are also described.

\section{Manufacturing sensors}

1. Cut appropriate cable lengths.

1. Determine the maximum distance from the data logger location to the desired sensor placement. Account for the additional cable length needed for bends in the cable, obstacles, and attachment to the data logger.

2. Cut all thermocouple and soil moisture cables to this maximum desired length. Differences in cable length may lead to variable resistances among sensors. This issue can be avoided by keeping all sensor cable lengths the same.

2. Prepare the thermocouple cable.

1. Strip the cable jacket $4-5 \mathrm{~cm}$ from the end of the cable.

2. Strip the newly exposed, small-diameter sheaths $5 \mathrm{~mm}$ from the end of the wires.

3. Arc weld together the exposed tips of the wires and test the strength of the new weld by tugging gently on the wires to ensure that they do not separate.

CAUTION: A welding helmet or face shield should be used to protect from the radiation generated when arc welding. Keep everything in the work environment dry to avoid potential shock. Work in a well-ventilated area to keep fumes or gases from your breathing area.

4. Dip the arc-welded tips of the thermocouple cable into liquid electrical tape to protect the exposed wires. The liquid electrical tape should cover the exposed metal of the wires and at least $3 \mathrm{~mm}$ of the small diameter wire sheaths.

CAUTION: Liquid electrical tape has flammable vapors that can irritate the respiratory tract. Use in a well-ventilated area away from open flames. Avoid direct exposure to the eyes and skin, as this can cause irritation.

5. Allow the liquid electrical tape to dry for approximately $4 \mathrm{~h}$ or as directed by the manufacturer.

6. Cut a piece of 0.13 in $(\sim 3.3 \mathrm{~mm})$ moisture-seal heat shrink tubing that is long enough to cover the liquid electrical tape on the small diameter sheaths and at least $1 \mathrm{~cm}$ of the thermocouple cable jacket (approximately $6 \mathrm{~cm} \mathrm{long}$ ). Insert the wires into the heat shrink tube and move the tube back over the cable jacket. Wait to apply heat until a later step (Step 1.5.3).

3. Prepare the soil moisture cable.

1. Strip the cable jacket $5 \mathrm{~cm}$ from the end of the cable.

2. Cut the ground wire (no sheath) off at the cable jacket so it is not exposed beyond the jacket.

3. Strip $1 \mathrm{~cm}$ of the inner small-diameter sheaths from the ends of the soil moisture wires.

4. Twist the exposed metal of each wire to consolidate the small strands.

5. Tin the small twisted strands by applying solder to the exposed metal at each wire end. CAUTION: Care should be taken when using the extremely hot instruments required for soldering. Solder in well-ventilated areas and wear appropriate eye and skin protection.

6. Cut a piece of 0.38 in $(\sim 10 \mathrm{~mm})$ heat shrink tubing that is $1 \mathrm{~cm}$ longer than the distance from where the cable jacket was stripped to the end of the tinned wires. Place this tube over both wires and slide it back over the cable jacket to fix into place at a later step.

7. Cut two $1.5 \mathrm{~cm}$ pieces of 0.13 in $(\sim 3.3 \mathrm{~mm})$ moisture-seal heat shrink tubing and place one over each wire. Do not heat these until you have soldered the wire to the two-prong socket strip.

8. Apply solder flux to the prongs of the two-prong socket strip. 
9. Solder the tinned ends of the wire to the ends of the two-prong socket strip. Be careful to keep the two ends separated so they are not touching.

10. Move the two pieces of 0.13 in $(\sim 3.3 \mathrm{~mm})$ moisture-seal heat shrink tubing to the base of the two-prong socket strip so that all metal parts are covered. Use the heat gun to adhere the heat shrink tubes, taking care not to overheat and melt the solder underneath the tubes.

11. Move the 0.38 in $(\sim 10 \mathrm{~mm})$ moisture-seal heat shrink tube to $1 \mathrm{~mm}$ from the end of the two-prong socket strip so that it is covering the socket strip, the small-diameter wires, and some of the cable jacket. Use the heat gun to fix this heat shrink tube in place.

4. Alter the terminal strip for the sensor head.

1. To modify the eight-prong terminal strip, orient the strip so the top prongs are curving away from view. Use wire snips to cut the second, fourth, and seventh prongs from the left just below the black plastic contact strip (Figure 2).

2. Measure $5 \mathrm{~mm}$ below the black plastic contact strip and mark the third, fifth, and sixth prongs from the left at $5 \mathrm{~mm}$. Snip these prongs at the $5 \mathrm{~mm}$ mark. This length can be modified to suit different research questions.

5. Assemble the sensor head.

1. Cut two $1 \mathrm{~cm}$ pieces of 0.5 in $(\sim 13 \mathrm{~mm})$ moisture-seal heat shrink tubing and slide one over each of the thermocouple and soil moisture cables.

2. Move the arc-welded end of the thermocouple wires over the top of the third clipped prong so that the tip of the thermocouple is oriented with the end of the clipped prong. Bend the wires so they follow the top curve of the prong.

3. Slide the 0.13 in $(\sim 3.3 \mathrm{~mm})$ moisture-seal heat shrink tube (from step 1.2.6) up over the curved part of the prong and the thermocouple wires. Check that the heat shrink tube is also covering part of the thermocouple cable jacket and use a heat gun to adhere the heat shrink tube in place. Squeeze the part of the heat shrink tube that is over the curved prong with fingers to secure it.

4. Insert the top curved ends of prongs 5 and 6 into the two-prong socket strip (Figure 2).

5. Move the top 0.5 in $(\sim 13 \mathrm{~mm})$ piece of moisture-seal heat shrink tube towards the sensor head so it is positioned approximately $1 \mathrm{~cm}$ from the head. Use a heat gun to adhere it in place, taking care to keep the socket strip firmly connected to prongs 5 and 6 and to the thermocouple wire on prong 3.

6. Use a heat gun to adhere the other $0.5 \mathrm{in}(\sim 13 \mathrm{~mm})$ piece of moisture-seal heat shrink tubing a few centimeters behind the previous piece of heat shrink tubing.

7. Apply liquid electrical tape to all sides of the thermocouple wire and prong 3.

8. Apply liquid electrical tape to all sides of the socket strip connection ensuring that all exposed metal is covered. Do not, however, cover the $5 \mathrm{~mm}$ clipped prongs associated with this connection (Figure 3 ).

\section{Connecting sensors to data logger and multiplexer}

NOTE: These sensors must be used with a multiplexer that is connected to a data logger. All steps in this protocol are for use with the data logger and multiplexer listed in the Table of Materials (other data loggers would also work). At each measurement time, the data logger opens communication to the multiplexer, which, in turn, acts as a relay and allows current to flow to the resistivity sensor.

1. Connect the multiplexer to the data logger using audio wires. Connect the COM port on the data logger to the RES port on the multiplexer. Connect the separate COM port on the data logger to the CLK port on the multiplexer. Connect the $\mathrm{G}$ and $12 \mathrm{~V}$ ports on the data logger to the GND and $12 \mathrm{~V}$ ports on the multiplexer, respectively.

2. Create a voltage divider on the data logger by connecting a through-hole $1 \mathrm{k} \Omega \pm 0.1 \%$ resistor between a VX port and an $H$ DIFF port on the data logger.

3. Connect two audio wires with a ground from this voltage divider to the multiplexer. Connect a wire from the same H DIFF port that the voltage divider is connected to on the data logger to the COM ODD L port on the multiplexer. Ensure that the other wire connects a ground port on the data logger to the COM ODD H port on the multiplexer. Ensure that a ground wire connects a ground from the data logger to a ground on the multiplexer.

4. Connect a Type $E$ thermocouple wire to the data logger and multiplexer. The purple wire connects the DIFF $1 \mathrm{H}$ port on the data logger to the COM EVEN H port on the multiplexer. The red wire connects the DIFF $1 \mathrm{~L}$ port on the data logger to the COM EVEN L port on the multiplexer. Ensure that the ground wire connects to a ground on both the data logger and multiplexer.

5. Change the multiplexer to $4 \times 16$ mode.

6. Connect the sensors to the multiplexer. Soil moisture audio cables connect to ODD ports with the black wire to $\mathrm{H}$ and the red wire to $\mathrm{L}$. Thermocouple wires connect to EVEN ports with the purple wire to $\mathrm{H}$ and the red wire to $\mathrm{L}$. The order of the thermocouple wires is crucial for proper measurements.

\section{Testing sensors}

1. Solder the ends of a film resistor to the prongs on a two-prong socket connector using lead solder and solder flux.

2. Connect all sensors to be tested to the multiplexer.

3. Adjust the data logging program to scan every $30 \mathrm{~s}$, or to a preferred frequency for scanning multiple sensors.

4. For moisture sensors, place the socket connector with film resistor onto prongs 5 and 6 of the sensor and record the data from the data logger.

5. Place the resistor on each sensor to ensure they all give the same reading.

6. Monitor the thermocouple data to ensure they are sensing similar temperatures.

7. For temperature sensors, place the thermocouple end between two fingers to make sure the temperatures change accordingly. 


\section{Calibrating sensors}

NOTE: This section describes the process for relating sensor output to soil moisture.

1. Manufacture the calibration sensor head.

1. Strip $12 \mathrm{~cm}$ of the jacket from the soil moisture cable.

2. Remove the foil shielding from the wires.

3. Cut a $10 \mathrm{~cm}$ length of both inner small-diameter soil moisture wires.

4. Strip approximately $1 \mathrm{~cm}$ of sheath off both ends of each wire.

5. Twist the small wires on each of the ends and tin them with a soldering iron.

6. Modify an eight-prong terminal strip to the same specifications as steps 1.4.1 and 1.4.2.

7. Apply solder flux to the top curves of prongs 5 and 6 .

8. Solder the wires to the top curves of prongs 5 and 6 on the eight-prong terminal strip.

9. Clip the two outer prongs of the eight-prong terminal strips to $5 \mathrm{~mm}$.

10. Place a $2 \mathrm{~cm}$ piece of 0.13 in $(\sim 3.3 \mathrm{~mm})$ moisture-seal heat shrink tubing onto both wires.

11. Adhere the heat shrink pieces as close to the modified sensor head as possible.

12. Place two $2 \mathrm{~cm}$ pieces of 0.13 in $(\sim 3.3 \mathrm{~mm})$ moisture-seal heat shrink tubing onto both wires, one on each wire. Wait to adhere them in place at a later step.

13. Cut the two long middle prongs of a four-prong terminal strip to $1 \mathrm{~cm}$.

14. Apply solder flux to the top curved ends of the middle prongs on the four-prong terminal strip.

15. Solder the free ends of both wires to the cut prongs of the four-prong terminal strip so that the top four curved prongs are facing away from the modified sensor head (Figure 4).

16. Move the previously placed moisture-seal heat shrink up to the base of the four-prong terminal strip and heat it into place.

2. Prepare the soil moisture cable for calibration.

1. Cut a soil moisture cable that is the same length as the sensors being used in the field.

2. Strip the jacket of the cable to $5 \mathrm{~cm}$ from the end.

3. Cut the ground wire (no sheath) off at the cable jacket so it is not exposed beyond the jacket.

4. Strip $1 \mathrm{~cm}$ of the small-diameter wire sheaths from the ends of the soil moisture wires.

5. Twist the exposed metal of each wire to consolidate the small strands.

6. Tin the small twisted strands by applying solder to the exposed metal at each wire end.

7. Cut a $6 \mathrm{~cm}$ piece of 0.38 in $(\sim 10 \mathrm{~mm})$ moisture-seal heat shrink tubing, place it over both wires, and slide it back over the cable jacket to adhere it at a later step.

8. Cut two $1.5 \mathrm{~cm}$ pieces of $0.13 \mathrm{in}(\sim 3.3 \mathrm{~mm})$ heat shrink tubing and place one over each wire. Do not apply heat until the wire is soldered to the two-prong socket strip.

9. Apply solder flux to the prongs of the two-prong socket strip.

10. Solder the tinned ends of the wire to the ends of the two-prong socket strip. Be careful to keep the two ends separated so they are not touching.

11. Move the two pieces of 0.13 in $(\sim 3.3 \mathrm{~mm})$ moisture-seal heat shrink tubing to the base of the two-prong socket strip so that all metal parts are covered. Use the heat gun to adhere the heat shrink tubes in place, taking care not to overheat and melt the solder underneath the tubes.

12. Move the 0.38 in $(\sim 10 \mathrm{~mm})$ moisture-seal heat shrink tube (from step 4.2.7) to $1 \mathrm{~mm}$ from the end of the two-prong socket strip so that it is covering the socket strip, the small-diameter wires, and some of the cable jacket. Use the heat gun to adhere the heat shrink tube in place.

3. Create the calibration soil container (Figure 5).

1. Cut a $50 \mathrm{~mL}$ polypropylene disposable centrifuge tube $4 \mathrm{~cm}$ from the top of the lid. This will create a tube with an opening at one end and a removable lid on the other.

2. Use a drill bit to drill a $2.5 \mathrm{~cm}$ hole in the center of the lid. A step drill bit is easy to use and effective.

3. Cut two vertical slits $6 \mathrm{~mm}$ apart, starting at the open end of the tube and extending to the bottom of the lid. Use a perpendicular cut at the bottom of the lid to connect the two slits and remove the plastic strip (Figure 5). This will create a large enough gap to insert the wires of the sensor head.

4. Cut a $6 \mathrm{~cm}$ diameter circular piece of polypropylene mesh cloth. Place the mesh between the lid and the tube and screw the lid on.

5. Insert the eight-prong terminal strip of the calibration sensor head into the tube so that the wires slide down the gap created in step 4.3.3.

6. Tape the longer prongs of the four-prong terminal strip to the side of the open end of the tube so that the upper prongs are facing away from the tube and can easily be connected to the two-prong socket strip of the calibration cable (Figure 5).

7. Place the container with attached sensor head in a $60^{\circ} \mathrm{C}$ drying oven for $48 \mathrm{~h}$ to remove any moisture.

4. Calibrate sensor and soil.

1. Weigh the empty, oven-dried calibration containers along with a calibration sensor head on a balance with $0.0001 \mathrm{~g}$ precision. This measurement will be used to calculate gravimetric water content (GWC) at a later step.

2. Conduct calibrations in an environment that can maintain a constant temperature.

3. Prepare biocrust soil for calibration.

4. Remove the lid of the calibration tube and use the threaded end as a mold to cut out a piece of biocrust of the same diameter. The biocrust should stay in the tube when pulled up but may require some assistance to keep it in the tube.

5. Using a finger, push the biocrust sample from the cut end of the tube so that 3-5 $\mathrm{mm}$ of the top of the biocrust remain in the tube. Scrape off any excess soil that is pushed out of the threaded end of the tube so that the bottom of the biocrust is flush with the bottom of the tube. 
6. Place the $6 \mathrm{~cm}$ diameter polypropylene mesh on the threaded end, below the biocrust, and screw the lid on tight.

7. Moisten the biocrust sample and gently fix the sensor head in the top of the substrate so the prongs are completely buried. The wires may need to be bent to ensure that the sensor head remains in place and does not move during the calibration.

8. Prepare mineral soil for calibration.

9. Collect soils from the upper $5 \mathrm{~mm}$ at the area where the sensors will be placed.

10. Use a $2 \mathrm{~mm}$ sieve to remove large rocks and organic material from the soil.

11. Ensure the lid is screwed on tight with the $6 \mathrm{~cm}$ diameter polypropylene mesh fixed between the lid and the tube.

12. Place sieved soil into the calibration container so it covers the bottom of the container to a $6 \mathrm{~mm}$ depth.

13. Moisten the soil sample and gently fix the sensor head in the top of the substrate so that the prongs are completely buried. The wires may need to be bent to ensure the sensor head remains in place and does not move during the calibration.

14. Saturate the substrate (biocrust or soil) with deionized water until a glossy water layer is visible at the surface.

15. Let the saturated substrate dry overnight.

16. Prior to starting any measurements, check that the sensor head is still in place and the prongs are all fully buried in the substrate.

17. Saturate the substrate with deionized water until a glossy layer is visible at the surface.

18. Dry the substrate for $15 \mathrm{~min}$.

19. Connect the two-prong socket strip of calibration soil moisture cable to the inner two prongs of the four-prong terminal strip.

20. Program the data logger to record measurements every minute.

21. Turn on the data logger to start collecting resistance measurements.

22. Position a fan to gently blow air over the calibration container when weights are not being recorded to promote drying.

23. Wet the substrate with deionized water until a sheen is visible at the surface.

24. Place the calibration container with wet soil on a paper towel to absorb dripping water.

25. Disconnect the calibration soil moisture wire from the four-prong terminal strip.

26. Lightly tap the container to expel dripping water.

27. Turn the fan off before placing the calibration container on the balance.

28. Place the container on the balance and record the weight and the time of measurement.

29. Reconnect the soil moisture wire to the four-prong terminal strip.

30. Place the calibration container back on to the paper towel.

31. Turn on the fan to expedite drying.

32. Record weights every 15 min until the substrate has completely air-dried. Complete drying is indicated by little or no change in the calibration container weights between measurements.

33. Place calibration container, calibration sensor head, and substrate in a $60{ }^{\circ} \mathrm{C}$ drying oven for $48 \mathrm{~h}$.

34. Weigh the oven-dried substrate, container, and sensor head.

5. Sensor calibration data analysis.

1. Calculate the dry substrate weight by subtracting the dry calibration container weight determined in step 4.4 .1 from the weight of the dry calibration container with substrate determined in step 4.4.34.

2. Calculate the water weight for each 15 -min timepoint or the calibration by subtracting the dry calibration container weight with substrate (step 4.4.34) from the weights recorded every $15 \mathrm{~min}$.

3. Calculate the GWC for each 15-min timepoint by dividing the water weights (step 4.5.2) by the dry soil weight (4.5.1).

4. Match resistance measurement times to the GWC of each 15-min timepoint determined in step 4.5.3.

5. Determine the calibration curve from regression analysis with GWCs as dependent variables and Siemens as independent variables (Figure 6). Different curve types (linear, power, logarithmic) may be most suitable for the calibration of different substrates.

\section{Representative Results}

Assessing the microclimate of the soil surface is essential for understanding and predicting the biological, chemical, and physical processes occurring there. These probes provide powerful opportunities to monitor microclimate at the very surface layer of the soil profile and are therefore valuable for assessments of biological activity occurring in the top few millimeters of the soil ${ }^{11,12}$. These probes were developed and refined to assess controls over biological soil crust activity because temperature and moisture in biocrust can be critical to its function ${ }^{2,8,10,12,15}$. However, while these probes were developed for photosynthetic soils in drylands, there is strong potential for implementing them in a wide range of systems, as well as to assess how temperature and moisture vary along soil depth profiles. For example, these sensors have been deployed in a tropical forest warming experiment to ascertain how warming treatments and natural variation in climate interact to determine covariations in soil processes, temperature, and moisture.

Nevertheless, there are some key considerations before implementing soil surface sensors. For example, calibration curves must be developed to convert units of resistance to more commonly used metrics of soil moisture, such as GWC. The soil surface sensor measures resistance between the metal prongs and outputs conductance (the inverse of resistance) values in Siemens (1/Ohm). Thus, conversion from Siemens to soil moisture must be performed. A number of chemical and physical properties of the soil substrate can affect the relationship between the sensor's conductance readings in Siemens and soil moisture. It is therefore critical to conduct substrate-specific calibrations to convert probe readings to soil moisture values. Calibration data from three substrates demonstrating these differences are shown.

Figure 6 depicts dry down calibration data for two samples each of three soil substrates, each with its own probe. Substrates were saturated fully until a small amount of water was visible at the surface. Probe resistances and soil weights were measured every 15 min until all samples were dry. Soil mass was subsequently used to calculate GWC. Figure 6 shows regressions of conductance and GWC for each sample. The substrates used for these calibrations include silt loam soils ( $23 \%$ sand, $64 \%$ silt, and $13 \%$ clay) collected at an experimental field station in El Yunque National Forest, Puerto Rico; moss-dominated biocrusts collected near Castle Valley, Utah; and fine sand soil (92\% sand, 3\% silt, and $5 \%$ clay) from experimental warming plots near Moab, Utah. 
The need for substrate-specific sensor calibrations is demonstrated by the variation in probe conductance and soil moisture for each substrate. For example, the regressions for the silt loam soil samples (Figure 6a) were distinct from the other two soil substrates. Therefore, applying the regression equation of the silt loam soil to moss biocrust, or vice versa, would lead to dramatically different values. On the other hand, the relationship between GWC and probe resistances for the fine sand soil (Figure 6c) and moss biocrust (Figure 6b) were similar. However, the fine sand soil was not able to hold as much water as the moss and correspondingly experienced much faster drying. As there is variation within substrates, it is important to have a large enough sample size to produce an accurate calibration curve and to create individual calibration curves for all sites.

In an experimental setting, these soil surface sensors were used to evaluate the treatment effects of a climate manipulation study near Moab, Utah, USA. This study used infrared lamps to increase ambient temperature of plots by $4{ }^{\circ} \mathrm{C}$ at the same location and with similar methods described by Wertin et al. ${ }^{17}$. Figure 7 shows average temperature and GWC from heated and control plots for two separate rain events that occurred in early May 2018. Average temperatures in the warmed plots were consistently higher than average temperatures of the control plots (Figure 7a). Over the course of these two rain events the resistivity sensors in the heated plots registered less soil moisture than the controls and the heated plots dried more quickly (Figure $7 \mathbf{b}$ ). It should be noted that increases in temperature can lead to higher conductivity of soils that must be accounted for ${ }^{19}$. The sensitivity of both the temperature and moisture components of these soil surface sensors allowed us to not only observe temperature differences of the warming treatment but also how it affected moisture dynamics in the plots.

The interactions of temperature and moisture were further investigated in an observational study using these soil surface sensors to analyze the timing of moisture availability to biocrusts during freeze-thaw conditions on the Colorado Plateau, USA. Sensors were placed into the top 5 $\mathrm{mm}$ of biocrusts that were composed primarily of the moss Syntrichia caninervis, and surface temperature and moisture were recorded during the months of January and February 2018. When temperatures were below $0{ }^{\circ} \mathrm{C}$, moisture at the surface of the moss was frozen, and the sensor output conductance values corresponded to $0 \%$ GWC (Figure 8). However, as temperatures exceeded $0{ }^{\circ} \mathrm{C}$, the frost melted at the moss surface and the liquid water registered on the resistivity sensor. In this instance, concurrent measurements of temperature and moisture showed how the variables interacted to potentially affect biological processes of organisms existing at the soil surface.

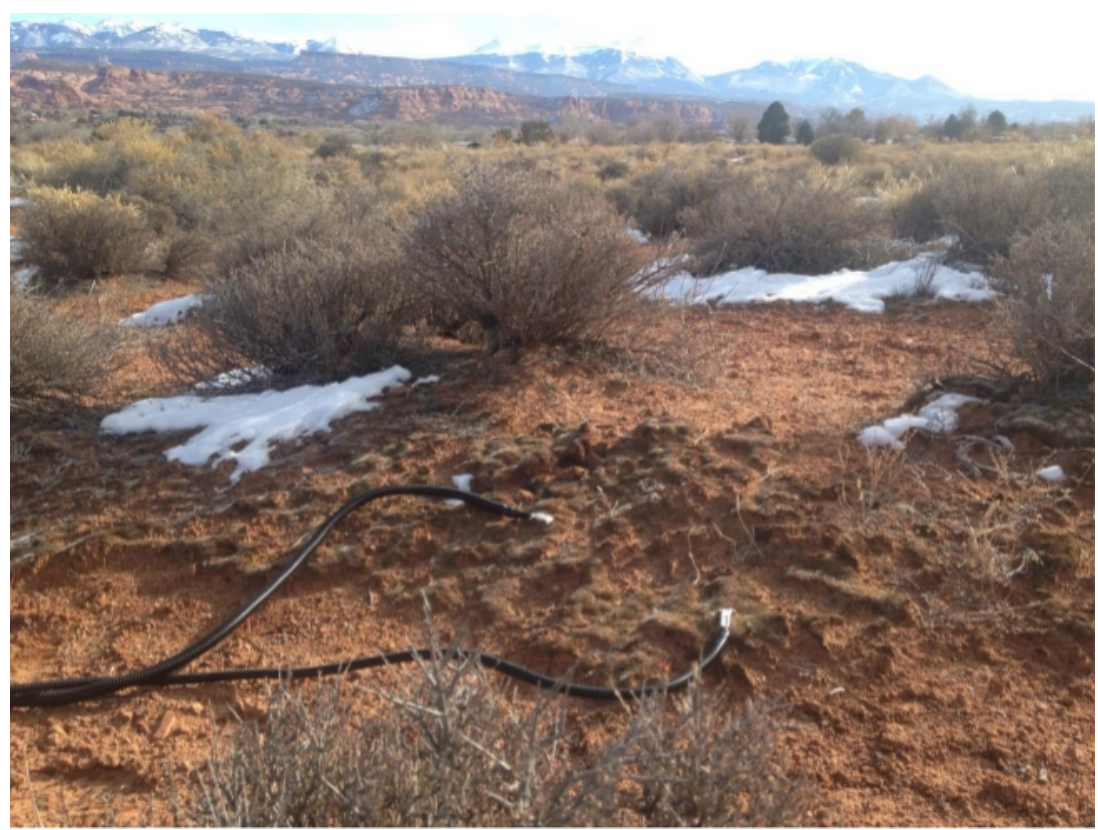

Figure 1: Biocrusted interspaces on the Colorado Plateau, USA. In many desert ecosystems the spaces between plants are often covered with biocrust communities composed of lichens, mosses, and cyanobacteria. Two soil temperature and moisture sensors were placed into the surface of moss biocrust. Please click here to view a larger version of this figure. 


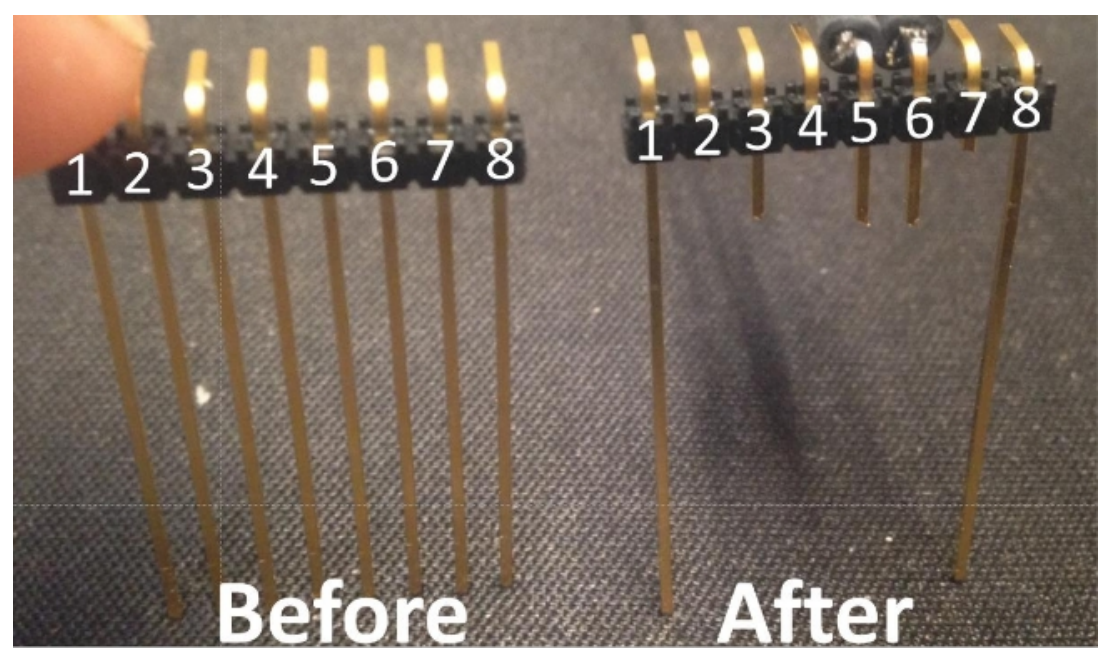

Figure 2: Clipping the eight-prong terminal strip. The gold-plated terminal strip is oriented with the top curved prongs facing away. The prongs are numbered 1 through 8, starting on the left and moving right. Prongs 2, 4, and 7 are cut flush with the bottom of the black plastic. Prongs 3,5 , and 6 are cut at $5 \mathrm{~mm}$ below the black plastic. Prong 3 stabilizes the arc-welded thermocouple wires, while resistance is measured between prongs 5 and 6 . These function as the soil moisture sensor. Prongs 1 and 8 serve as holdfasts in the soil. Please click here to view a larger version of this figure.

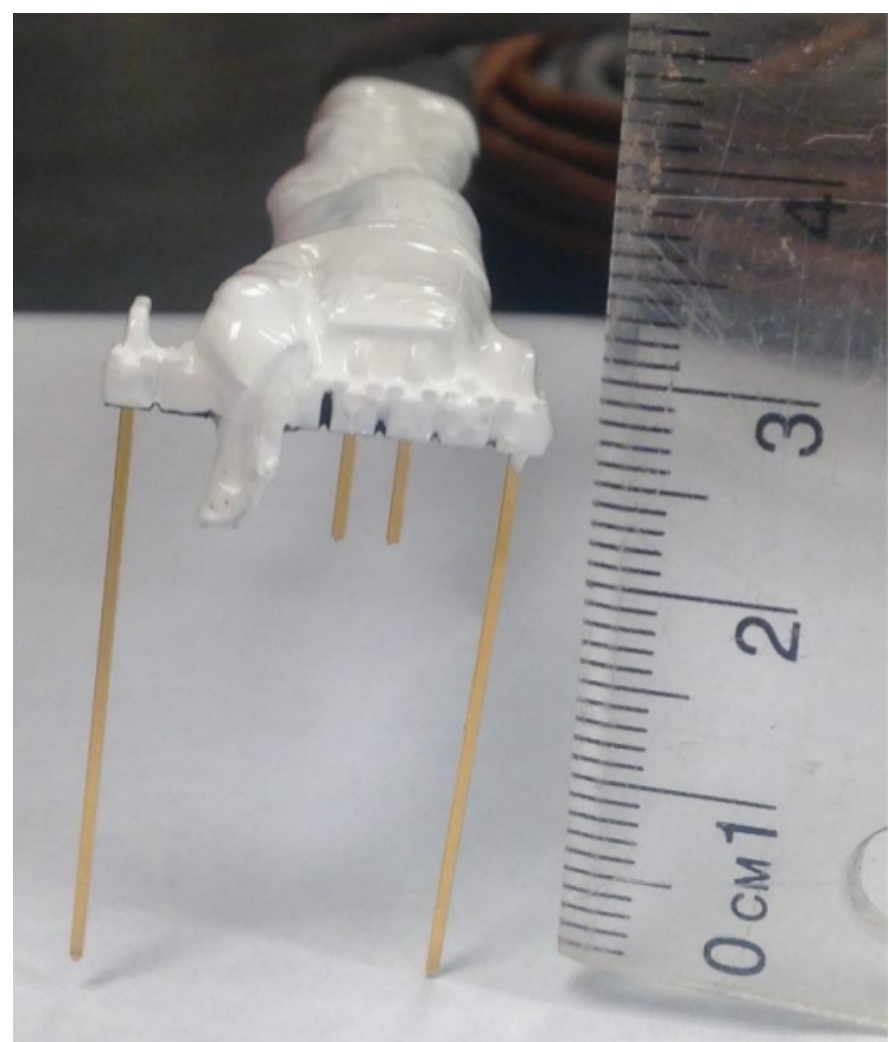

Figure 3: Finished sensor head. The modified sensor head and thermocouple cable are covered with liquid electrical tape. It is important to keep prongs 5 and 6 (the moisture sensor) clean and not coated with liquid electrical tape to ensure there is no contamination that would affect resistance measurements. Please click here to view a larger version of this figure. 


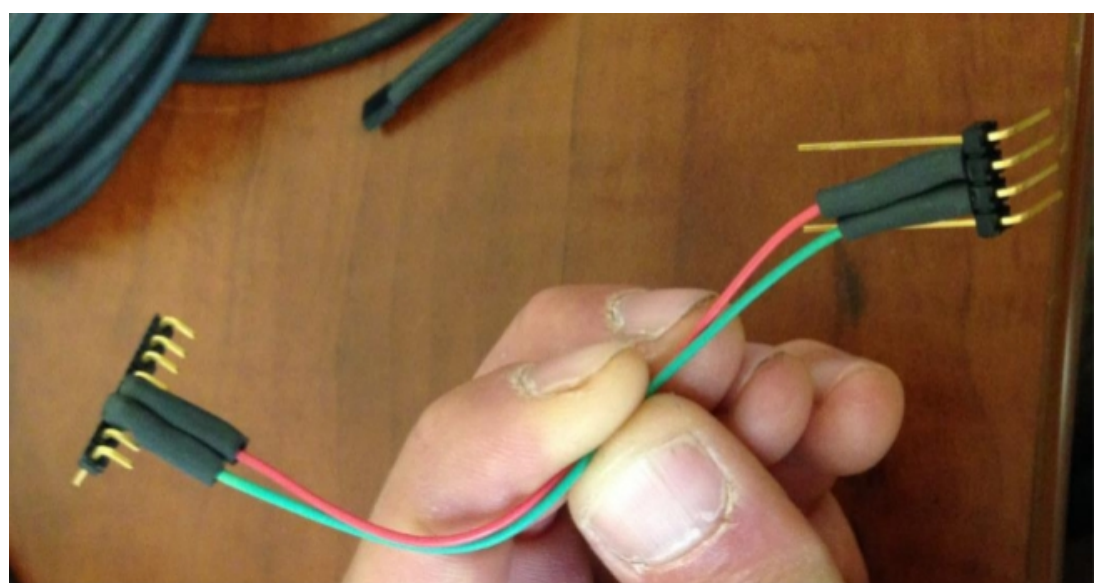

Figure 4: Calibration sensor head. The four-prong terminal strip is soldered to the wires so that it faces away from the modified sensor head. Moisture seal heat shrink is fixed in place close to the terminal strips to prevent crosstalk between the wires. Please click here to view a larger version of this figure.

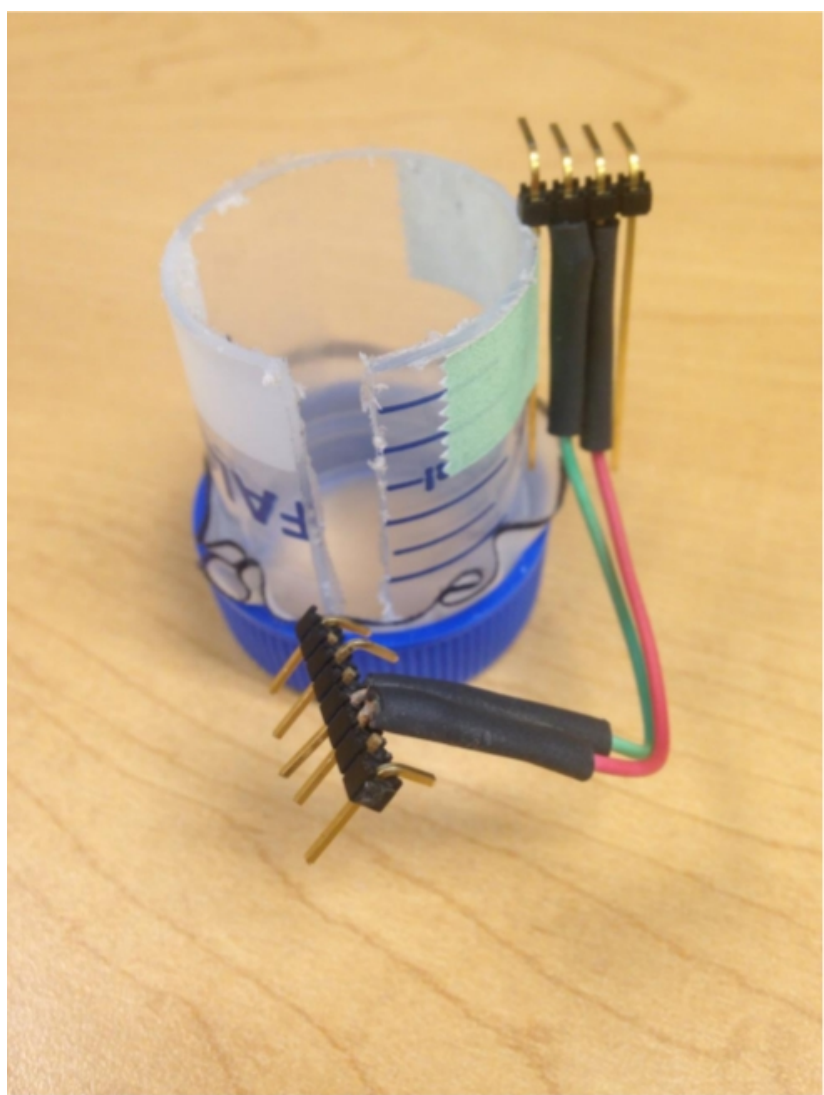

Figure 5: Calibration container and sensor head. The four-prong terminal strip is taped to the container and oriented so that it can easily be connected to a two-prong socket strip. This placement allows the sensor head to be placed into the cut slit and fixed into the substrate of interest. Please click here to view a larger version of this figure. 


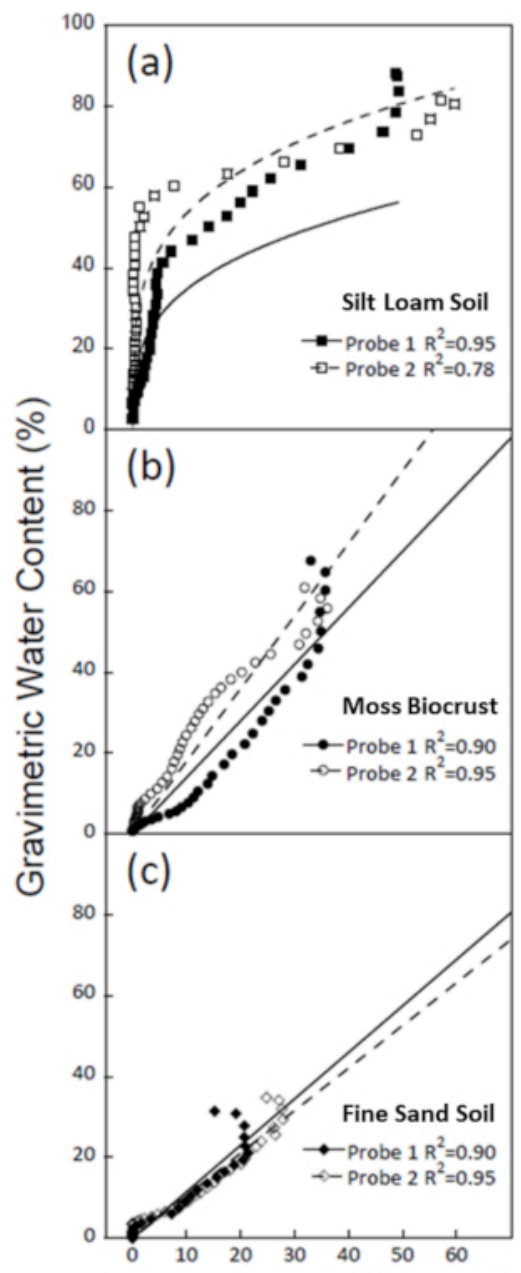

Sensor Output (Siemens)

Figure 6: Sensor calibrations for three soil substrates. Calculated gravimetric water content (GWC) percentages, determined by measuring soil mass during substrate dry-down, were compared with soil sensor conductance values from the probes (measured in Siemens). Data shown are for two samples from each of three distinct soil substrates. Soil substrates were (a) a silt loam soil, (b) a moss biocrust, and (c) a fine sand soil. (a) The relationship of GWC and conductance values in predominantly silt loam soils was best represented by a power regression. (b) A strong linear relationship of GWC and sensor conductance was observed for biocrusts dominated by the moss Syntrichia caninervis. (c) A linear regression best represented the relationship between GWC and sensor conductance measurements in fine sand soils. At high GWC values the conductance values diverge from the calibration curve, indicating a potential limitation of the sensors when soils are saturated. Please click here to view a larger version of this figure. 


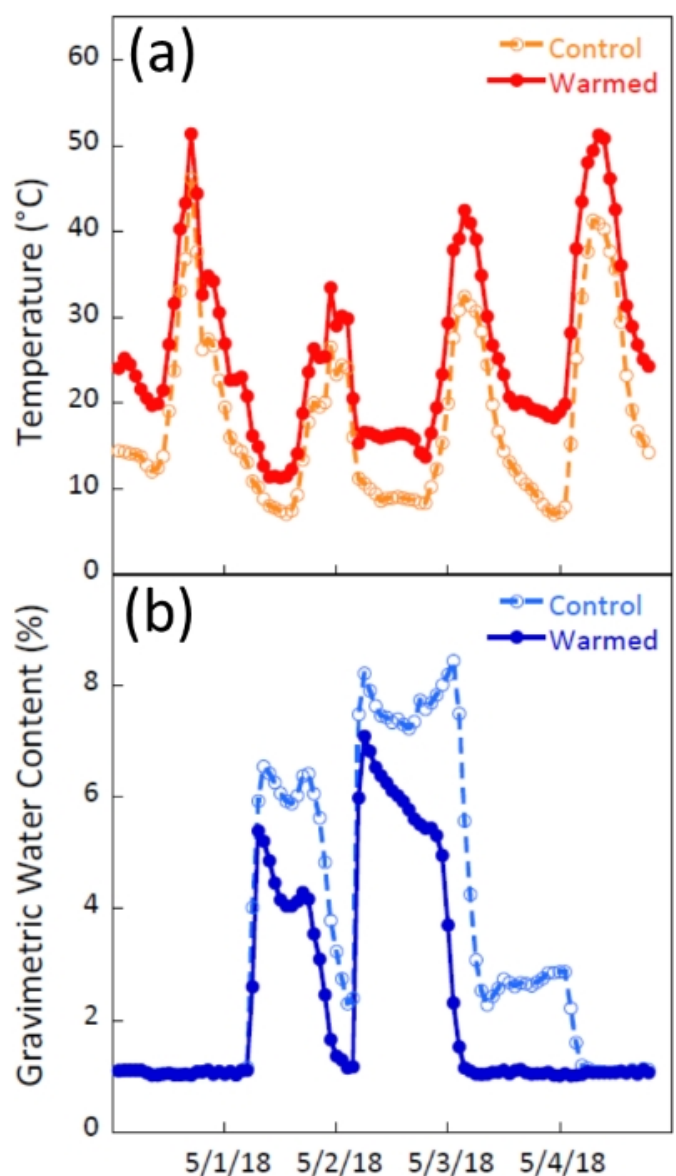

Figure 7: Temperature and gravimetric water content with field infrared warming treatments. Hourly average surface temperature and GWC recorded at 10-min intervals in 5 warmed and 5 control plots over 4 days. Data are from a global change experiment in a semi-arid steppe ecosystem on the Colorado Plateau, USA ${ }^{17}$. Data show that soil surface sensors captured treatment effects. (a) Average temperatures at the soil surface were consistently higher in the warmed plots. (b) The effects of warming were also apparent in the GWC values, showing that warmed plot soils maintained faster drying times. Please click here to view a larger version of this figure. 


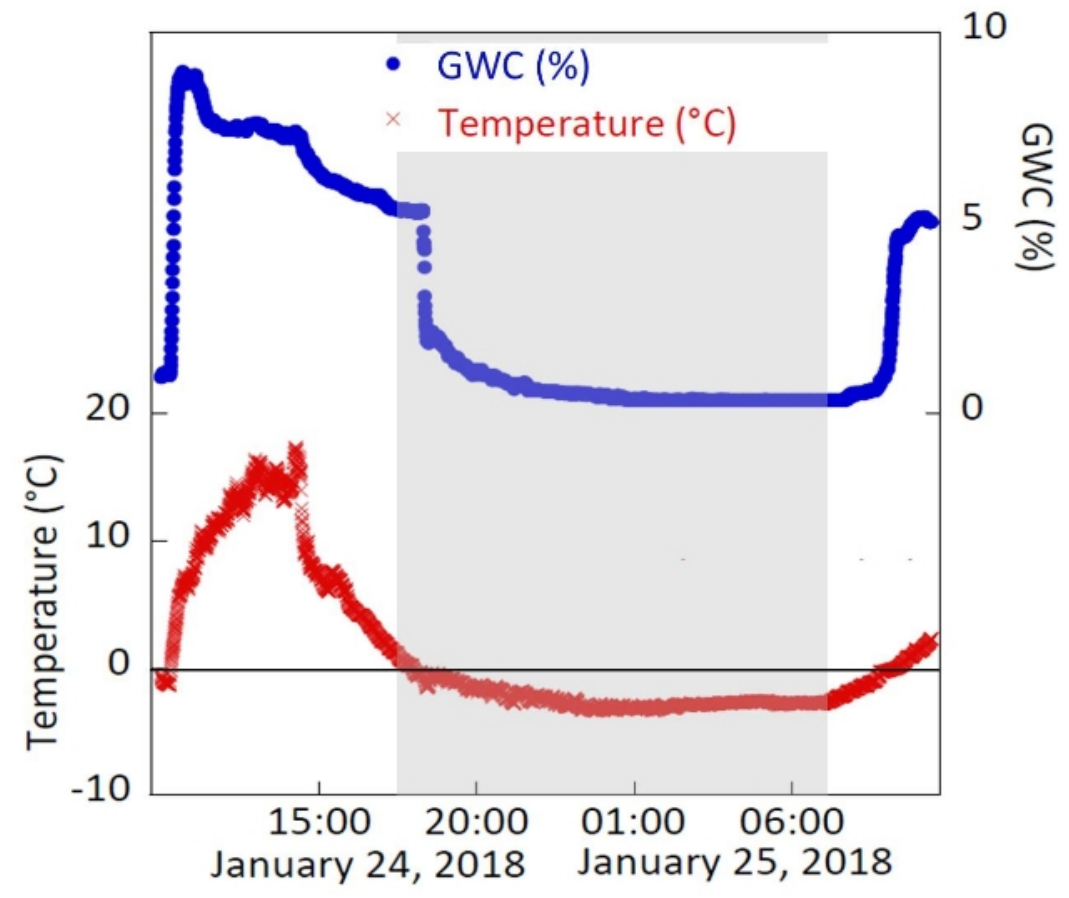

Figure 8: Moss biocrust temperature and gravimetric water content during frost events. Average surface temperature and GWC of four replicates of Syntrichia caninervis moss biocrusts recorded at 10-min intervals from 9:50 AM January 24, 2018 to 11:20 AM January 25, 2018. Nighttime hours are represented in the grey shaded area and daytime hours in the unshaded areas. When water was frozen in the form of frost on the moss surface, there was no conductance measured by the sensor. Thus, the GWC was 0 . Freezing conditions occurred shortly after nightfall as soil temperature dropped below $0{ }^{\circ} \mathrm{C}$. Thawing occurred shortly after sunrise as temperatures rose above $0{ }^{\circ} \mathrm{C}$, when the frost melted, and the liquid water was detected by the sensors. These results demonstrate the effectiveness of the sensors at distinguishing liquid water and ice, which may have important implications for a range of biological processes. Please click here to view a larger version of this figure.

\section{Discussion}

Soil surface temperature and moisture probes can be effective tools for analyzing temperature and water content at the soil surface. Except for the Biocrust Wetness Probes (BWP) developed by Weber et al. ${ }^{11}$, common soil temperature and moisture sensors do not explicitly measure these environmental variables at the top few millimeters of the soil surface. At the time of development, the BWPs only estimated soil moisture at the surface and not the temperature ${ }^{20}$. With the original BWP design used as a guide, the probes described in this manuscript were developed to simultaneously measure temperature and moisture to assess how these environmental variables interact with each other, as well as with biological, chemical, and physical processes at the soil surface.

There are a number of considerations to ensure optimal operation of these probes. While building the sensor, it is important to take care not to cut through the inner sheaths and expose the underlying metal wires. This can lead to variation in conductance and crosstalk among the wires. It is also critical to test both the thermocouples and resistivity sensors for each probe in the same environment, to confirm that they are properly constructed and that variations in readings are due to physical and chemical differences in the soil substrate being measured. During the calibration process, a large enough sample number of resistance and GWC calibrations is critical to properly account for variation in soil or biocrust substrates. Also, it is best to test the same probe and substrate combination twice, from wet to dry, as it is common for these probes to 'drift' over time due to electrolysis or corrosion. Additionally, during calibration it is important to use shallow substrate samples that are only deep enough to accommodate the probe length (i.e., between 6 and $7 \mathrm{~mm}$ ), so that measured water weights are from water primarily in the area of the conductance measurements (between and around the probes). This ensures that changes in water mass in the soils are directly related to changes in resistance measurements of the probes. Finally, when deploying these probes in the field, it is important to properly secure the probes to the soil surface (e.g., with nonconductive garden stakes), which will limit interference in conductance measurements but can ensure the sensors do not shift position and diminish the quality of long-term measurements.

It is also important to note some limitations of these sensors. Because the resistivity probes are only $5 \mathrm{~mm}$ long, their measurements can be strongly affected by large air-filled pore spaces in substrates. Large air gaps along the probes decrease connectivity of the substrate and generally lead to lower measured conductivity and therefore lower estimated water content, which may not be reflective of the actual soil moisture across larger scales. Similarly, the chemical composition of soils can affect soil moisture readings. Higher salinity will increase conductivity and lead to higher Siemens values ${ }^{21}$. Both issues should be resolved with proper substrate-specific calibrations. However, some soils may maintain chemical differences or have large pore space architecture that could make them poor environments for these sensors. Temperature also affects the electrical conductivity of soils and thus must be considered ${ }^{15}$. In the future, temperature calibrations with these sensors should be conducted to determine how temperatures change the resistance of measured substrates.

Like the Biocrust Wetness Probes developed by Weber et al. ${ }^{11}$, these sensor calibrations show that resistance measurements are reliable at medium water contents, but that they experience some abnormalities at very high and low water contents (Figure 6). In addition, during dry- 
down calibrations, resistance values occasionally read zero when there was still some water present in the substrate sample. This could be due to the amount of substrate in the calibration container being slightly larger than the area measured by the sensor. If water was present outside of the resistivity area, the sensor would read zero while the substrate still had moisture present. Care was taken to decrease substrate size without compromising resistance measurements. As water content increases, resistance values within the substrate decrease, leading to higher Siemens outputs. However, at the highest water contents, resistance values increase with increasing water content. This leads to a "hook" in the calibration data as seen in Figure 1C. This hook was present in each substrate used for calibrations but was most prominent in the fine sand soils (Figure 6). Weber et al. ${ }^{\uparrow 1}$ suggests that a potential cause for abnormal resistance increases at high water contents is that additional water dilutes ions in saturated soils, thereby increasing resistance.

These sensors are currently dependent upon using existing multiplexer and data logger technologies. The multiplexer allows the sensors to be "turned off" and only sends a current to the sensors at a programmed time. This prevents the soil moisture sensor terminals from corroding. Other electronic companies provide data logger and multiplexer alternatives for the probes, and programmable circuit boards and computers could also be incorporated for a wireless design of soil temperature and moisture sensors, which could represent an exciting advance.

Designing and building sensors allows the researcher to customize the probes. The length and direction of the prongs can be manipulated to better assess moisture in different mediums or at different depths. Custom wiring can be ordered to allow for designs with multiple sensor heads emanating from the same cable. With the addition of inexpensive data logging and multiplexer options, these sensors provide an inexpensive and accessible option for researchers to measure temperature and soil moisture at the soil surface. This includes measuring hard to capture events, such as frost and dew formation (Figure 8), and experimental treatment effects such as warming (Figure 7). This paper provides a stepby-step guide for building soil surface sensors that simultaneously measure temperature and moisture, which can be used and refined by anyone interested in assessing the environment of biocrust communities and the surficial layers of many other soil types.

\section{Disclosures}

The authors have nothing to disclose.

\section{Acknowledgments}

We thank Robin Reibold for his careful arc-welding and Cara Lauria for her precision during calibrations. We are grateful to Dr. Steve Fick and three anonymous reviewers for their helpful comments on a previous draft of this manuscript. This work was supported by the U.S. Geological Survey Land Change Science Program and the U.S. Department of Energy Office of Science, Office of Biological and Environmental Research Terrestrial Ecosystem Sciences Program (Awards 89243018SSC000017 and DESC-0008168). The work of BW was supported by the German Research Foundation (Grants WE2393/2-1, 2-2), the Max Planck Society and by the University of Graz. Any use of trade, firm, or product names is for descriptive purposes only and does not imply endorsement by the U.S. Government.

\section{References}

1. Phillipot, L., Hallin, S., Schloter, M. Ecology of denitrifying prokaryotes in agricultural soil. Advances in Agronomy. (ed. Sparks, D.L.), San Francisco, CA, USA, Elsevier B.V. 96, 249-30, (2007).

2. Grote, E. E., Belnap, J., Housman, D. C., Sparks, J. P. Carbon exchange in biological soil crust communities under differential temperatures and soil water contents: implications for global change. Global Change Biology. 16 (10), 2763-2774 (2010).

3. Thompson, K., Grime J. P., Mason G. Seed Germination in response to diurnal fluctuations in temperature. Nature. 267, 147-149 (1977)

4. Doneen, L. D., MacGillivray, J. H. Germination (emergence) of vegetable seed as affected by different soil moisture conditions. Plant Physiology. 18 (3), 524-529 (1943).

5. Kirshbaum, M. U. F. The temperature dependence of soil organic matter decomposition, and the effect of global warming on soil organic $C$ storage. Soil Biology and Biochemistry. 27 (6), 753-760 (1995).

6. Garcia-Pichel, F. et al. Small-scale vertical distribution of bacterial biomass and diversity in biological soil crusts from arid lands in the Colorado Plateau. Microbial Ecology. 46, 312 (2003).

7. Belnap, J., Büdel, B., Lange, O. L. Biological Soil Crusts: Structure, Function, and Management (eds. Belnap, J., Lange, O.), Springer Berlin Heidelberg. 150, 263-279, (2003).

8. Darrouzet-Nardi, A., Reed, S. C., Grote, E. E., Belnap, J. Observations of net soil exchange of $\mathrm{CO}_{2}$ in a dryland show experimental warming increases carbon losses in biocrust soils. Biogeochemistry. 126, 363-378 (2015)

9. Rutherford, W. A., et al. Albedo feedbacks to future climate via climate change impacts on dryland biocrust. Scientific Reports. 7, 44188 (2017).

10. Maestre, F. T., et al. Changes in biocrust cover drive carbon cycle responses to climate change in drylands. Global Change Biology. 19 (12), 3835-3847 (2013).

11. Weber, B., et al. Development and calibration of a novel sensor to quantify the water content of surface soils and biological soil crusts. Methods in Ecology and Evolution. 7, 14-22 (2016).

12. Tucker, C. L., et al. The concurrent use of novel soil surface microclimate measurements to evaluate $\mathrm{CO}_{2}$ pulses in biocrusted interspaces in a cool desert ecosystem. Biogeochemistry. 135 (3), 239-249 (2017)

13. Pierson, F. B., Wight, J. R. Variability of near-surface soil temperature on sagebrush rangeland. Journal of Range Management. 44 (5), 491-497 (1991).

14. Jin, M., Dickenson, R. E. Land surface skin temperature climatology: benefitting from the strengths of satellite observations. Environmental Research Letters. 5 (4), 044004 (2010).

15. Lange, O. L. Photosynthesis of soil-crust biota as dependent on environmental factors. Biological soil crusts: characteristics and distribution. In: Biological Soil Crusts: Structure, Function, and Management. (eds. Belnap, J., Lange, O.), 18, 217-240. Springer Berlin Heidelberg (2003). 
16. Davidson, E. A., Janssens, I. A., Luo Y. On the variability of respiration in terrestrial ecosystems: moving beyond $Q_{10}$. Global Change Biology. 12 (2), 154-164 (2005).

17. Wertin, T. M., Belnap J., Reed, S. C. Experimental warming in a dryland community reduced plant photosynthesis and soil $\mathrm{CO}_{2}$ efflux although the relationship between the fluxes remained unchanged. Functional Ecology. 31, 297-305 (2017).

18. Darrouzet-Nardi, A., Reed, S. C., Grote, E. E., Belnap, J. Patterns of longer-term climate change effects on $\mathrm{CO}_{2}$ efflux from biocrusted soils differ from those observed in the short term. Biogeosciences. 15 (14), 4561-4573 (2018).

19. McNeill, D. J. Rapid, Accurate Mapping of Soil Salinity by Electromagnetic Ground Conductivity Meters. Soil Science Society of America. $\mathbf{3 0}$, 209-229 (1992).

20. Scholz, S., Ruckteschler, N., Gypser, S. Weber, B. Determination of drying and rewetting cycles of moss-dominated biocrusts using a novel biocrust wetness probe. Poster session presented at GfÖ Annual Meeting. (2018).

21. Rhoades, J. D., Ingvalson, R. D. Determining Salinity in Field Soils with Soil Resistance Measurements. Soil Science Society of America. 35 (1), 54-60 (1971). 